\title{
Verbetering van continentie door urethrasparende robotgeassisteerde laparoscopische prostatectomie
}

\author{
Kim Hulshof · Niek F. Casteleijn · Marloes Vermeer · J. Herman Roelink · Erik B. Cornel · Saskia P. Stomps
}

Geaccepteerd op: 19 april 2021 / Published online: 6 mei 2021

(C) The Author(s) 2021

\begin{abstract}
Samenvatting Incontinentie is een veelvoorkomend probleem na robotgeassisteerde laparoscopische prostatectomie (RALP), wat impact heeft op de kwaliteit van leven. Urethrasparende chirurgie reduceert mogelijk het risico op incontinentie in deze patiëntengroep. Het doel van deze studie is te onderzoeken welk effect urethrasparende RALP (URALP) heeft op incontinentie. Alle patiënten die tussen mei 2014 en januari 2019 een conventionele RALP of een URALP ondergingen werden geïncludeerd. Continentie werd postoperatief geobjectiveerd na 6 weken, 3, 6, 9 en 12 maanden met behulp van een 24 -uurs padtest en werd gedefinieerd als het gebruik van maximaal 1 safety pad per 24 uur. Na zes weken was $42,5 \%$ van de RALP-patiënten continent vs. $82,1 \%$ van de URALP-patiënten, een significant verschil $(p<0,001)$. Dit verschil was na 12 maanden nog steeds significant $(87,5 \%$ vs. $98,4 \%, p<0,001)$. Gebaseerd op deze veelbelovende resultaten suggereren wij dat urethrasparende RALP als operatietechniek van eerste keuze wordt toegepast voor een snellere en grotere kans op continentie na RALP.
\end{abstract}

Trefwoorden robotgeassisteerde laparoscopische prostatectomie (RALP) · urethrasparende techniek · continentie

\author{
drs. K. Hulshof · dr. N. F. Casteleijn · drs. J. H. Roelink · \\ dr. E. B. Cornel $\cdot$ drs. S. P. Stomps $(\bowtie)$ \\ afdeling Urologie, Ziekenhuis Groep Twente, Almelo, \\ Nederland \\ s.stomps@zgt.nl \\ dr. N. F. Casteleijn \\ afdeling Urologie, Universitair Medisch Centrum Groningen, \\ Groningen, Nederland \\ dr. M. Vermeer \\ ZGT Academie, Ziekenhuis Groep Twente, Almelo, \\ Nederland
}

\section{Continence improvement after urethral preserving robot assisted laparoscopic prostatectomy}

\begin{abstract}
Incontinence is a common complication after robot assisted laparoscopic prostatectomy (RALP) that can have major impact on quality of life. Urethral preserving surgery could possibly reduce the risk of incontinence in this patient group. The aim of this study is to investigate the effect of the urethral preserving RALP technique (URALP) on incontinence rates. All conventional RALP and urethral preserving RALP were included in this study from May 2014 till January 2019. Continence was postoperatively observed after 6 weeks, 3, 6, 9 and 12 months and was defined as maximal use of 1 safety pad per day. After 6 weeks significantly more URALP patients were continent (82.1\% URALP vs. $42.5 \%$ RALP, $p<0.001)$, and this difference remained significant after 12 months (98.4\% URALP vs. $87.5 \%$ RALP, $p<0.001$ ). Based on our promising findings we suggest incorporating the urethral preserving method as the first choice RALP technique to improve incontinence after RALP.
\end{abstract}

Keywords robot assisted laparoscopic prostatectomy (RALP) · urethral preserving technique $\cdot$ continence

\section{Introductie}

Een van de ingrijpende gevolgen van robotgeassisteerde laparoscopische prostatectomie (RALP) is incontinentie, een klacht die grote impact heeft op de kwaliteit van leven. Uit de Nederlandse RALP-database van 2017 blijkt dat bij ongeveer $20 \%$ van de patiënten 12 maanden na de ingreep nog incontinentieklachten voorkomen [1]. Bekkenbodemfysiotherapie kan zorgen voor verbetering van continentie, maar een deel van de patiënten blijft incontinent. 

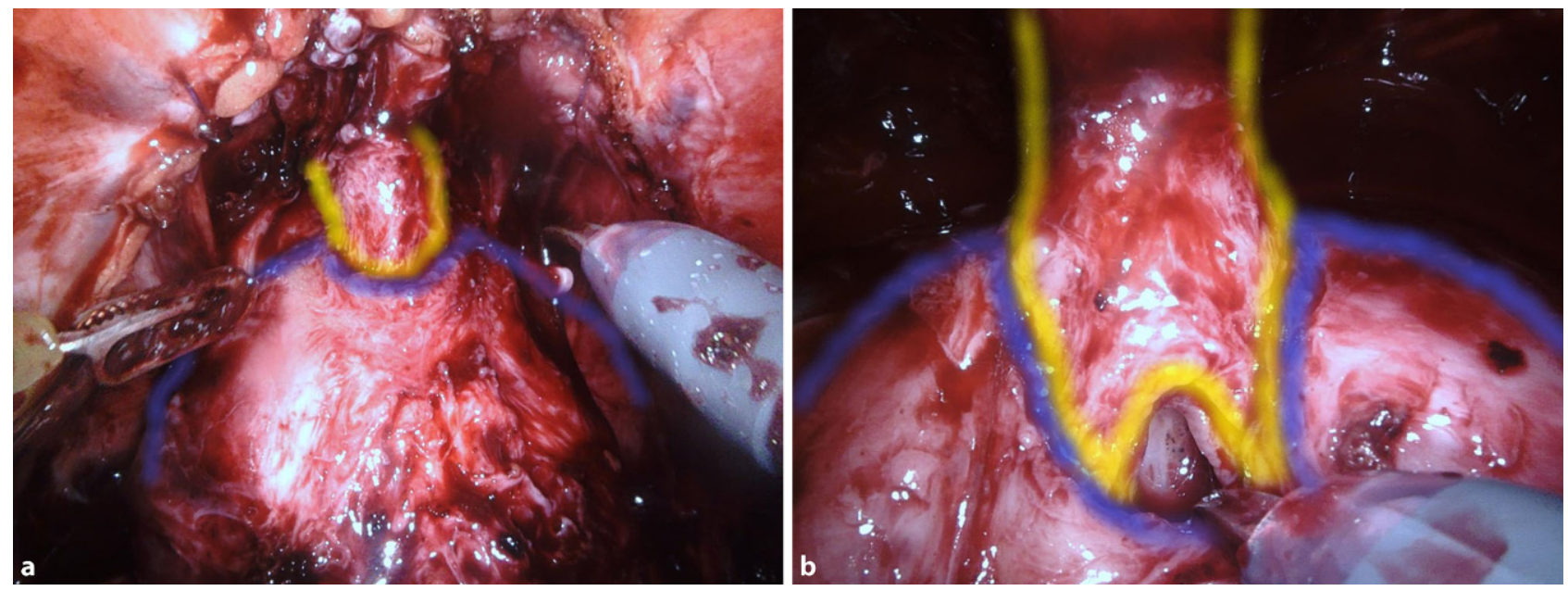

Figuur 1 Peroperatieve beelden apicale dissectie van de prostaat. a Het niveau van het doornemen van de urethra gedurende RALP. b Het niveau van het doornemen van de urethra gedurende de URALP

Behoud van urethrale lengte heeft mogelijk een positieve impact op verbetering van de continentie van deze groep. Verschillende studies laten zien dat lengte van de membraneuze urethra positief geassocieerd is met vroege continentie na RALP. Zowel een grotere preoperatieve lengte van de membraneuze urethra gemeten via MRI als perioperatief lengtebehoud van de urethra is gecorreleerd met een sneller herstel van continentie postoperatief [2-5].

In de literatuur worden verschillende technieken om urethrale lengte te behouden, geëvalueerd. Schlomm et al. beschrijven een complexe operatieve reconstructie en een specifieke hechttechniek in meerdere lagen met enerzijds behoud van lengte van de urethra en anderzijds behoud van fixatie van de urethra in de bekkenbodem [6]. Deze technisch complexe benadering resulteert in continentie in de helft van de patiënten 14 dagen na RALP, wat een verbetering is van $20 \%$ ten opzichte van de conventionele techniek. Na 12 maanden rapporteerden respectievelijk $96,9 \%$ en $94,7 \%$ van de patiënten in deze studie dat er sprake was van continentie. Ondanks dat een groter deel van de urethra gespaard wordt, leidt deze techniek niet tot toename in positieve snijvlakken [6].

Gezien de complexiteit van de methode die wordt beschreven door Schlomm et al. werd er in Ziekenhuisgroep Twente (ZGT) een gesimplificeerde variant geïntroduceerd. Deze nieuwe variant is uitsluitend gericht op behoud van urethrale lengte. Hierbij wordt het anatomische vlak tussen de urethra en de apex geopend en naar proximaal afgeschoven. De urethra wordt zo vrijgeprepareerd tot aan de colliculus seminales en ter plaatse doorgenomen. De afstand tussen de externe sfincter en de anastomose wordt hierdoor groter en het sfinctercomplex blijft zo ruim mogelijk gespaard. De anastomose wordt vervolgens gemaakt zoals gebruikelijk met een voortlopende dubbelgearmeerde V-lock. De rocco- en suspensiehechtingen werden onveranderd uitgevoerd. Middels deze tech- niek kan er een urethrale lengtewinst van 1 tot $1,5 \mathrm{~cm}$ worden verkregen (fig. 1).

Het doel van deze studie is om deze gemodificeerde urethrasparende techniek te toetsen op continentieuitkomsten en te onderzoeken of deze techniek een nadelig effect heeft op de oncologische uitkomst.

\section{Materiaal en methoden}

In Ziekenhuisgroep Twente worden jaarlijks tussen de 140 en 170 robotgeassisteerde prostatectomieën uitgevoerd. Alle patiënten werden geïncludeerd tussen december 2014 en januari 2019. Vanaf mei 2017 wordt de RALP uitgevoerd middels de gemodificeerde urethrasparende techniek. Alle patiënten zijn sindsdien middels de urethrasparende techniek geopereerd, ongeacht tumorstadium of tumorlocatie op de preoperatieve MRI. Bij alle patiënten werd preoperatief een MRI-scan verricht, tenzij er sprake was van een contra-indicatie. De urethralengte werd preoperatief niet gemeten. Rekening houdend met de leercurve van de urologen werden patiënten tussen mei 2017 en december 2017 niet meegenomen in analyse. Zowel de URALP als RALP werden uitgevoerd door dezelfde twee urologen. De procedure werd door beide urologen in gelijke aantallen verricht. De preparaten werden postoperatief verwerkt door de patholoog. De preparaten werden gefixeerd op $4 \%$ gebufferde formaline. De coupes van 2 micron $(\mu \mathrm{m})$ dik werden met hematoxylline eosine gekleurd.

Patiënten bij wie geen 12 maanden follow-up was geregistreerd, werden geëxcludeerd. Data werd verkregen betreffende patiëntkarakteristieken, preoperatieve gegevens, perioperatieve gegevens en postoperatieve complicaties. Patiënten werden minimaal vervolgd voor 12 maanden. Continentie werd gemeten 6 weken en 3, 6, 9 en 12 maanden postoperatief met behulp van een padtest waarbij de patiënt het aantal pads per 24 uur dat hij op dat moment gebruikte, no- 


\section{Artikel}

Tabel 1 Patiëntkarakteristieken en continentieaantallen na RALP

\begin{tabular}{|c|c|c|c|}
\hline & $\begin{array}{l}\text { RALP } \\
(n=300)\end{array}$ & $\begin{array}{l}\text { URALP } \\
(n=207)\end{array}$ & $p$-waarde \\
\hline leeftijd (jaren) & $66 \pm 6$ & $66 \pm 5$ & 0,8 \\
\hline initieel PSA (ng/ml) & $7,9(6-11)$ & $8,0(6-12)$ & 0,6 \\
\hline prostaatvolume TRUS (ml) & $45 \pm 22$ & $43 \pm 19$ & 0,3 \\
\hline prostaatvolume MRI (ml) & $49 \pm 22$ & $54 \pm 29$ & 0,1 \\
\hline klinische stagering, $\%$ & & & 0,3 \\
\hline$-\mathrm{T} 1 \mathrm{c}$ & $203(67,7)$ & $122(58,9)$ & \\
\hline$-\mathrm{T} 2 \mathrm{a}$ & $54(18,0)$ & $32(15,5)$ & \\
\hline$-\mathrm{T} 2 \mathrm{~b}$ & $23(7,6)$ & $25(12,1)$ & \\
\hline$-\mathrm{T} 2 \mathrm{C}$ & $9(3,0)$ & $12(5,8)$ & \\
\hline$-\mathrm{T} 3 \mathrm{a}$ & $7(2,3)$ & $13(6,3)$ & \\
\hline - overig & $4(1,4)$ & $3(1,4)$ & \\
\hline MRI-stadiëring, \% & & & 0,2 \\
\hline$-\mathrm{T} 2$ & $127(42,3)$ & $97(46,9)$ & \\
\hline$-\mathrm{T} 3 \mathrm{a}$ & $117(39,0)$ & $75(36,2)$ & \\
\hline$-\mathrm{T} 3 \mathrm{~b}$ & $15(5,0)$ & $7(3,3)$ & \\
\hline - overig & $41(13,7)$ & $28(13,6)$ & \\
\hline ISUP gradering groep (na RALP), \% & & & 0,08 \\
\hline-1 & $134(44,7)$ & $75(36,2)$ & \\
\hline-2 & $99(33,0)$ & $67(32,4)$ & \\
\hline-3 & $35(11,7)$ & $32(15,5)$ & \\
\hline$-4-5$ & $32(10,6)$ & $33(15,9)$ & \\
\hline \multicolumn{4}{|l|}{ pathologische stagering } \\
\hline - pathologische stagering T2, $\%$ & $185(61,7)$ & $124(59,9)$ & 0,6 \\
\hline - pathologische stagering T3-T4, \% & $115(38,3)$ & $82(39,6)$ & 0,6 \\
\hline - overig & - & $1(0,5)$ & \\
\hline operatietijd (min) & $227 \pm 71$ & $235 \pm 70$ & 0,2 \\
\hline snijvlakken, \% & & & 0,2 \\
\hline$-\mathrm{RO}$ & $201(67,0)$ & $152(73,4)$ & \\
\hline - R1 totaal & $99(33,0)$ & $55(26,6)$ & \\
\hline - R1 (apex/ventraal) & $47(15,7)$ & $31(15,0)$ & \\
\hline \multicolumn{4}{|l|}{ zenuwsparing, \% } \\
\hline - geen & $94(31,3)$ & $58(28,0)$ & \\
\hline - unilateraal & $105(35,0)$ & $73(35,3)$ & \\
\hline - bilateraal & $101(33,7)$ & $76(36,7)$ & \\
\hline \multicolumn{4}{|l|}{ continentie percentages, $\%$} \\
\hline - na 6 weken & $127(42,5)$ & $170(82,1)$ & $<0,001$ \\
\hline - na 3 maanden & $181(60,7)$ & $191(92,7)$ & $<0,001$ \\
\hline - na 6 maanden & $233(79,5)$ & $197(96,1)$ & $<0,001$ \\
\hline - na 9 maanden & $246(84,2)$ & $198(97,1)$ & $<0,001$ \\
\hline - na 12 maanden & $258(87,5)$ & $183(98,4)$ & 0,004 \\
\hline biochemisch recidief na 12 maanden, \% & $17(5,7)$ & $10(4,8)$ & 0,1 \\
\hline
\end{tabular}

teerde. Vanaf 2019 werden ook PROMS uitgevraagd. De uitkomsten van de PROMS kwamen overeen met de resultaten van de padtest waarbij beide dus gelijkwaardig gebruikt konden worden. Continentie werd gedefinieerd als gebruik van 0 tot 1 safety pad per dag. Patiënten werden ingedeeld in twee groepen: RALP zonder urethrasparing en RALP met urethrasparing (URALP). De raad van bestuur van ZGT heeft het studieprotocol geëvalueerd en geoordeeld dat ons stu- dieprotocol geen METC-goedkeuring nodig heeft; de studie werd beschouwd als geprotocolleerde patiëntenzorg.

\section{Statistische analyse}

Er is gebruikgemaakt van beschrijvende statistiek: gemiddelden met standaarddeviaties (SD) voor continue variabelen die normaal verdeeld zijn, de mediaan 
Figuur 2 Postoperatieve continentiepercentages van URALP en RALP

\section{Continentiepercentages per groep}

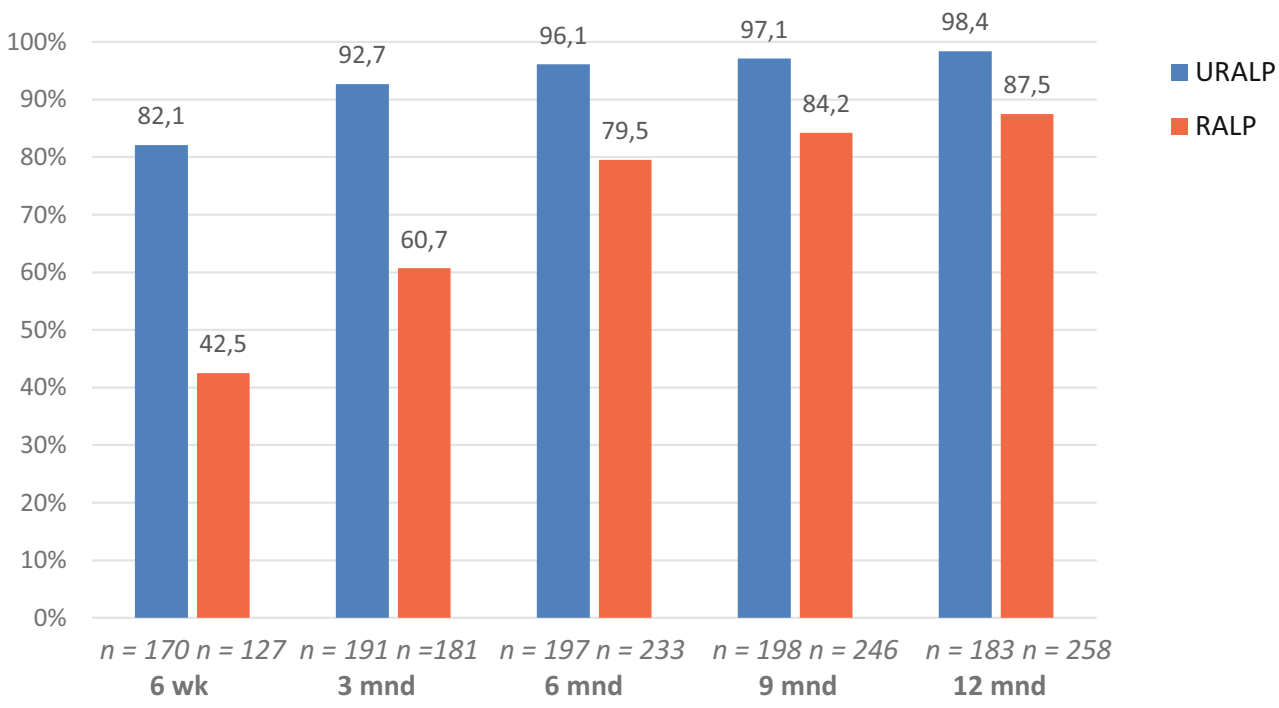

met interkwartiel range (IKR) voor continue variabelen die niet normaal verdeeld zijn en aantallen met percentages voor categoriale variabelen. Verschillen tussen de groepen werden getoetst met de onafhankelijke t-test (normaal verdeelde variabelen), MannWhitney U test (niet-normaal verdeelde variabelen) of de Chi-kwadraattoets (categoriale variabelen). Een $p$-waarde $<0,05$ werd beschouwd als statistisch significant en alle statistische tests werden tweezijdig uitgevoerd.

\section{Resultaten}

In totaal werden 507 patiënten geïncludeerd, 207 in de URALP-groep en 300 in de RALP-groep (tab. 1). De gemiddelde leeftijd in beide groepen was 66 jaar met een initieel PSA van $8 \mathrm{ng} / \mathrm{ml}$ in de URALP-groep en $7,9 \mathrm{ng} / \mathrm{ml}$ in de RALP-groep. Het volume van de prostaat op echo en MRI was respectievelijk $43 \mathrm{ml}$ en $54 \mathrm{ml}$ in de URALP-groep en $45 \mathrm{ml}$ en $49 \mathrm{ml}$ in de RALPgroep. Er werden geen significante verschillen gevonden tussen de URALP- en RALP-groep, behoudens een trend bij ISUP-gradering, waarbij $15,5 \%$ van de patiënten in de URALP-groep in ISUP-gradering 3 viel ten opzichte van $11,7 \%$ van de patiënten in de RALPgroep. In de ISUP-gradering groep 4-5 was dit respectievelijk 15,9 en $10,6 \%$.

$\mathrm{Na}$ zes weken was $42,5 \%$ van de patiënten continent in de RALP-groep ten opzichte van $82,1 \%$ in de URALP-groep, een significant verschil $(p<0,001)$ (fig. 2). Dit verschil bleef significant gedurende followup in het eerste jaar. Na 12 maanden bleek uiteindelijk $87,5 \%$ continent in de RALP-groep en $98,4 \%$ in de URALP-groep $(p<0,001)$. In beide groepen nam de continentie significant toe ten opzichte van de continentie na 6 weken $(p<0,001)$. De urethrasparende techniek resulteerde niet in een hoger totaal aantal positieve snijvlakken vergeleken met de RALP- groep (URALP $26,6 \%$ vs. RALP 33,0\%; $p=0,2$ ). Ook ter hoogte van de apex, waar de urethra bij deze techniek gespaard wordt, werd geen toename van positieve snijvlakken gezien (URALP $15 \%$ vs. RALP 15,7\%; $p=0,2)$. Dit gold ook voor patiënten met een ISUPgradering hoger dan 2 of Gleason-score van $4+3$ en hoger (URALP 29,8\% vs. RALP 43,7\%; $p=0,3$ ). Het biochemisch recidief na 12 maanden was gelijk in beide groepen (URALP $4,8 \%$ vs. RALP $5,7 \% ; p=0,1$ ).

\section{Discussie}

Deze studie laat in een patiëntenpopulatie van meer dan 500 patiënten zien dat een eenvoudig toe te passen urethrasparende techniek bij RALP resulteert in verbeterde vroege en late continentie. $\mathrm{Na} 12$ maanden is $98,4 \%$ van de patiënten continent zonder toename van positieve snijvlakken. Een veelbelovend resultaat dat kan bijdragen aan de verbetering van de kwaliteit van leven van patiënten die een RALP ondergaan.

Incontinentie is een veelvoorkomend probleem na RALP. Uit de Nederlandse registratie blijkt dat continentie wordt bereikt bij $80-90 \%$ van de patiënten 12 maanden na RALP [1]. Ook in onze studie wordt een continentie van $87,5 \%$ na RALP gerapporteerd. Door de negatieve impact van incontinentie op de kwaliteit van leven is het noodzakelijk om zowel het aantal gevallen van incontinentie als de duur van de incontinentie te reduceren. Urethrasparende RALP kan hierbij een veelbelovende oplossing zijn.

Verschillende studies laten zien dat behoud van urethralengte resulteert in toename van continentie. Deze studies gebruiken allemaal hun eigen techniek voor urethrabehoud. Zo beschrijven Schlomm et al. een complexe hechttechniek in meerdere lagen met enerzijds behoud van de lengte van de urethra en anderzijds behoud van de fixatie van de urethra in de bekkenbodem [6]. Hamada et al. beschrijven een 
complexe urethrasparende techniek waarbij door het losmaken van fibreuze strengen ter plaatse van de apex van de prostaat een additionele urethrale lengte wordt verkregen, waarover zij rapporteren dat alle patiënten na 12 maanden continent zijn. Hierbij moet echter wel een kanttekening worden gemaakt omdat in deze studie slechts 30 patiënten volgens deze techniek werden geopereerd [7]. Heo et al. beschrijven een gecombineerde techniek van urethrapreservatie in combinatie met blaashalspreservatie. In een cohort van 305 patiënten die deze gecombineerde ingreep ondergingen, was na vier weken $73,4 \%$ continent en $98,7 \%$ na 12 maanden [8]. Al deze studies rapporteren zowel vroege continentie (na enkele weken) als een hoog percentage continentie na 12 maanden, zelfs tot $100 \%$. Deze verschillende methoden zijn echter zodanig complex dat ze naar onze mening niet breed toepasbaar zijn in een algemene urologische kliniek. Daarnaast neemt de kosteneffectiviteit van de RALP af doordat de genoemde technieken relatief veel operatietijd kosten. De door ons geïntroduceerde gemodificeerde urethrasparende techniek is eenvoudig, effectief en veilig. Met onze resultaten laten we zien dat we met een gesimplificeerde techniek, uitgevoerd in een middelgroot ziekenhuis, gelijkwaardige continentiecijfers kunnen realiseren als Schlomm vanuit de Martini Kliniek Hamburg.

In het licht van de opvatting van Thompson et al. zouden onze resultaten kunnen worden uitgelegd als onderdeel van de leercurve [9]. Zij beschrijven dat er 300 robotgeassisteerde prostatectomieën nodig zijn voor een verbetering in continentie-, seksuele en oncologische uitkomsten. Beide urologen hebben voor de start van de urethrasparende RALP ongeveer 150 robotgeassisteerde prostatectomieën per persoon uitgevoerd. De resultaten hiervan zijn in lijn met het landelijk gemiddelde. Daarom kan gesteld worden dat de leercurve voor de conventionele RALP reeds bereikt is. De significante, niet-lineaire verbetering van continentie is naar onze mening het gevolg van de URALP en kan deze niet alleen door de verbetering ten gevolge van de leercurve worden uitgelegd.

In theorie kan de urethrasparende RALP leiden tot slechtere oncologische uitkomsten. Zeker bij carcinomen ter plaatse van de apex zou de urethrasparende techniek kunnen leiden tot een groter aantal positieve snijvlakken. Onze studie toont echter geen verschil in positieve snijvlakken tussen beide groepen; dit geldt voor zowel het totale aantal positieve snijvlakken, als het aantal positieve snijvlakken ter plaatse van de apex. Bovendien ligt het totale aantal positieve snijvlakken bij URALP in ons onderzoek op $26,6 \%$, wat onder het landelijk gemiddelde ligt van $28,9 \%$ [1]. We kunnen dus concluderen dat urethrasparende RALP niet leidt tot een groter risico op positieve snijvlakken.

Een beperking van deze studie is het retrospectieve single center design zonder dat er sprake is van randomisatie. Slechts twee urologen voeren in ons centrum de (U)RALP uit. Hoewel er geen randomisatie heeft plaatsgevonden, zijn we van mening dat beide groepen met elkaar kunnen worden vergeleken. Patiënten tumorkarakteristieken zijn namelijk niet significant verschillend. Een andere beperking is dat er aanvankelijk geen gebruik is gemaakt van gevalideerde vragenlijsten voor het verzamelen van de urologische resultaten. Er werd in 2019 gestart met PROMS, de uitkomsten van deze PROMS kwamen overeen met de uitkomsten van de padtest, dit maakt dat wij van mening zijn de padtest goed te kunnen gebruiken.

\section{Conclusie}

Urethrasparende RALP (URALP) is een eenvoudig aan te leren techniek die zorgt voor een evident groter aantal patiënten met vroege én late continentie zonder negatief effect op de oncologische uitkomst. Continentie na 12 maanden neemt significant toe van $87,5 \%$ naar $98,4 \%$. Gebaseerd op onze resultaten suggereren wij dat de urethrasparende techniek als operatietechniek van eerste keuze bij RALP wordt toegepast bij patiënten met prostaatcarcinoom om zo kwaliteit van leven te verbeteren.

Open Access This article is distributed under the terms of the Creative Commons Attribution 4.0 International License (http://creativecommons.org/licenses/by/4.0/), which permits unrestricted use, distribution, and reproduction in any medium, provided you give appropriate credit to the original author(s) and the source, provide a link to the Creative Commons license, and indicate if changes were made.

\section{Literatuur}

1. nvukwaliteit.nl.. https://www.nvukwaliteit.nl. Geraadpleegd op: 15 aug 2018.

2. Ikarashi D, Kato Y, Kanehira M, et al. Appropriate preoperative membranous urethral length predicts recovery of urinary continence after robot-assisted laparoscopic prostatectomy. World J Surg Oncol. 2018;16(1):224.

3. Coakley FV, Eberhardt S, Kattan MW, Wei DC, Scardino PT, Hricak H. Urinary continence after radical retropubic prostatectomy: relationship with membranous urethral length on preoperative endorectal magnetic resonance imaging. JUrol. 2002;168(3):1032-5.

4. Kim M, ParkM,PakS, etal. Integrity of the urethral sphincter complex, nerve-sparing, and long-term continence status after robotic-assisted radical prostatectomy. Eur Urol Focus. 2019;5(5):823-30.

5. Haga N, Ogawa S, Yabe M, et al. Factors contributing to early recovery of urinary continence analyzed by preand postoperative pelvic anatomical features at robotassisted laparoscopic radical prostatectomy. J Endourol. 2015;29(6):683-90.

6. Schlomm T, Heinzer H, Steuber T, et al. Full functional-length urethral sphincter preservation during radical prostatectomy. Eur Urol. 2011;60(2):320-9.

7. Hamada A, Razdan S, Etafy MH, Fagin R, Razdan S. Early return of continence in patients undergoing robot-assisted laparoscopic prostatectomy using modified maximal urethral length preservation technique. J Endourol. 2014;28(8):930-8. 
8. Heo JE, Lee JS, Goh HJ, Jang WS, Choi YD. Urethral realignment with maximal urethral length and bladder neck preservation in robot-assisted radical prostatectomy: Urinary continence recovery. PLoS ONE. 2020;15(1):1-11.

9. Thompson JE, Egger S, Böhm M, et al. Superior quality of life and improved surgical margins are achievable with robotic radical prostatectomy after a long learning curve: a prospective single-surgeon study of 1552 consecutive cases. Eur Urol. 2014;65(3):521-31. drs. Kim Hulshof, anios urologie

dr. Niek F. Casteleijn, uroloog in opleiding

dr. Marloes Vermeer, klinisch epidemioloog

drs. J. Herman Roelink, uroloog

dr. Erik B. Cornel, uroloog

drs. Saskia P. Stomps, uroloog 